\title{
Shape transformation of Sn nanocrystals induced by swift heavy-ion irradiation and the necessity of a molten ion track
}

\author{
R. Giulian, ${ }^{1}$ F. Kremer, ${ }^{2}$ L. L. Araujo, ${ }^{1}$ D. J. Sprouster, ${ }^{1}$ P. Kluth, ${ }^{1}$ P. F. P. Fichtner, ${ }^{2}$ A. P. Byrne, ${ }^{1}$ and M. C. Ridgway ${ }^{1}$ \\ ${ }^{1}$ Research School of Physics and Engineering, Australian National University, Canberra, ACT 0200, Australia \\ ${ }^{2}$ Instituto de Física, Universidade Federal do Rio Grande do Sul, Av. Bento Gonçalves 9500, Ciaxa Postal 1501, CEP 91501-970, \\ Porto Alegre, Rs, Brazil
}

(Received 7 June 2010; revised manuscript received 2 September 2010; published 24 September 2010)

\begin{abstract}
We report on the spherical to rodlike shape transformation of Sn nanocrystals (NCs) embedded in amorphous $\mathrm{SiO}_{2}$ following irradiation with $185 \mathrm{MeV}$ Au ions. Consistent with previous reports for other metals, transmission electron microscopy demonstrates that under irradiation, Sn NCs larger than a critical size (11 $\mathrm{nm}$ ) elongate parallel to the incident ion direction, while smaller particles remain spherical. Irradiation-induced $\mathrm{NC}$ dissolution is significant, as evident from the formation of smaller NCs in place of their original larger counterparts. Using formation conditions that yield $\mathrm{Sn} \mathrm{NCs}$ at the amorphous- $\mathrm{SiO}_{2} /$ crystalline-Si interface, we show that the irradiation-induced shape change occurs only within the $\mathrm{SiO}_{2}$ layer, in the direction opposite to that of the incident ions. We suggest this demonstrates the necessity of a molten ion track and provides further evidence for an elongation process involving $\mathrm{NC}$ melting and flow.
\end{abstract}

DOI: 10.1103/PhysRevB.82.113410

PACS number(s): 61.80.-x, 61.46.Hk, 68.37.Lp

\section{INTRODUCTION}

Swift heavy-ion irradiation (SHII) of metallic nanocrystals (NCs) embedded in amorphous $\mathrm{SiO}_{2}\left(\mathrm{a}-\mathrm{SiO}_{2}\right)$ has been intensely investigated since D'Orleans et al. ${ }^{1}$ showed that ion irradiation in the electronic energy-loss regime resulted in $\mathrm{NC}$ deformation under certain conditions. The first reports on Co were followed by investigations on $\mathrm{Pt},{ }^{2,3} \mathrm{Au},{ }^{4-8} \mathrm{Ag},{ }^{9}$ and other metallic NCs (Refs. 10 and 11) in an attempt to identify the mechanism(s) responsible for the observed shape and structural changes and aid in the development of devices where the properties of aligned, anisotropically shaped NCs could be exploited. . $^{1,12,13}$

The need for a surrounding matrix in the shape transformation process was demonstrated upon comparison with free standing metallic NCs (Ref. 6) given the latter did not change shape. Previously, we suggested the formation of an irradiation-induced molten ion track in $\mathrm{a}-\mathrm{SiO}_{2}$ also plays an important role in the shape transformation process ${ }^{2,10}$ and measured the diameter of such a track in $\mathrm{a}_{-} \mathrm{SiO}_{2}(\sim 11 \mathrm{~nm})$ for the same irradiation conditions used herein. ${ }^{2}$ In general, metallic NCs in $\mathrm{a}_{-} \mathrm{SiO}_{2}$ irradiated to sufficiently high fluences exhibit saturation of the width or minor dimension $\left(D_{\text {minor }}\right)$ of the elongated NCs and this value appears to be limited by the diameter of the molten ion track in a- $\mathrm{SiO}_{2}$ $\left(D_{\text {track }}\right)$. For example, $D_{\text {minor }}$ (saturation $)=D_{\text {track }}$ for Au NCs (Ref. 4) while $D_{\text {minor }}$ (saturation) $<D_{\text {track }}$ for $\mathrm{Pt}$ and Co NCs. ${ }^{2,10}$ As such, we also suggested that the saturation of $D_{\text {minor }}$ is metal specific and influenced by the thermodynamic properties of the NC material. ${ }^{10}$

We now report on the shape transformation of Sn NCs by SHII. Our results contribute to a better understanding of the shape transformation mechanism of embedded metallic NCs under SHII and demonstrate the necessity of a molten ion track during the process. Sn has considerably lower melting and vaporization temperatures as well as a lower cohesive energy relative to the metals previously investigated and as a consequence may aid in identifying the relationship between the shape transformation mechanism and the aforementioned intrinsic thermodynamic properties of the $\mathrm{NC}$ metal.

\section{EXPERIMENTAL}

Two Sn NC ensembles of different size and depth distributions were produced. To form $\mathrm{Sn} \mathrm{NCs}$ within an a-SiO layer, a $2-\mu$ m-thick a- $\mathrm{SiO}_{2}$ film was thermally grown on a crystalline $\mathrm{Si}(\mathrm{c}-\mathrm{Si})$ substrate and sequentially implanted


$7 \times 10^{16} \mathrm{~cm}^{-2}$ and $3 \times 10^{16} \mathrm{~cm}^{-2}$, respectively, yielding a near constant Sn concentration of 8 at. \% over depths of 90-190 nm below the surface. Samples were then annealed in vacuum for $30 \mathrm{~min}$ at $1000{ }^{\circ} \mathrm{C}$ to produce spherical metallic Sn NCs with a broad size distribution. To form NCs at or in close proximity to the a-SiO $/$ c-Si interface, a 200-nmthick a- $\mathrm{SiO}_{2}$ film thermally grown on a c-Si substrate was implanted with $200 \mathrm{keV} \mathrm{Sn}{ }^{+}$ions to a fluence of $2 \times 10^{16} \mathrm{~cm}^{-2}$. Samples were then annealed in a two-step process, first at $200{ }^{\circ} \mathrm{C}$ for $100 \mathrm{~h}$ at ambient atmosphere followed by $1100{ }^{\circ} \mathrm{C}$ for $2 \mathrm{~h}$ in vacuum. ${ }^{15}$

For the SHII, samples were aligned perpendicular to the incident ion direction and irradiated at room temperature with $185 \mathrm{MeV} \mathrm{Au}$ ions to fluences of $\leq 2 \times 10^{14} \mathrm{~cm}^{-2}$. At this energy, the electronic energy loss over the extent of the a- $\mathrm{SiO}_{2}$ layer is effectively constant at $\sim 17 \mathrm{keV} / \mathrm{nm}$ while the nuclear energy loss is two orders of magnitude lower. ${ }^{16}$

Transmission electron microscopy (TEM) was performed using a Phillips CM300 microscope operating at $300 \mathrm{kV}$ with samples prepared in cross-sectional geometry. The minor and major dimensions of the Sn NCs were manually measured from representative micrographs and a minimum of $\sim 500$ NCs were examined for statistical reliability.

\section{RESULTS AND DISCUSSION}

Figure 1(a) shows a representative TEM image of Sn NCs embedded in $\mathrm{a}-\mathrm{SiO}_{2}$ following SHII to a fluence of 

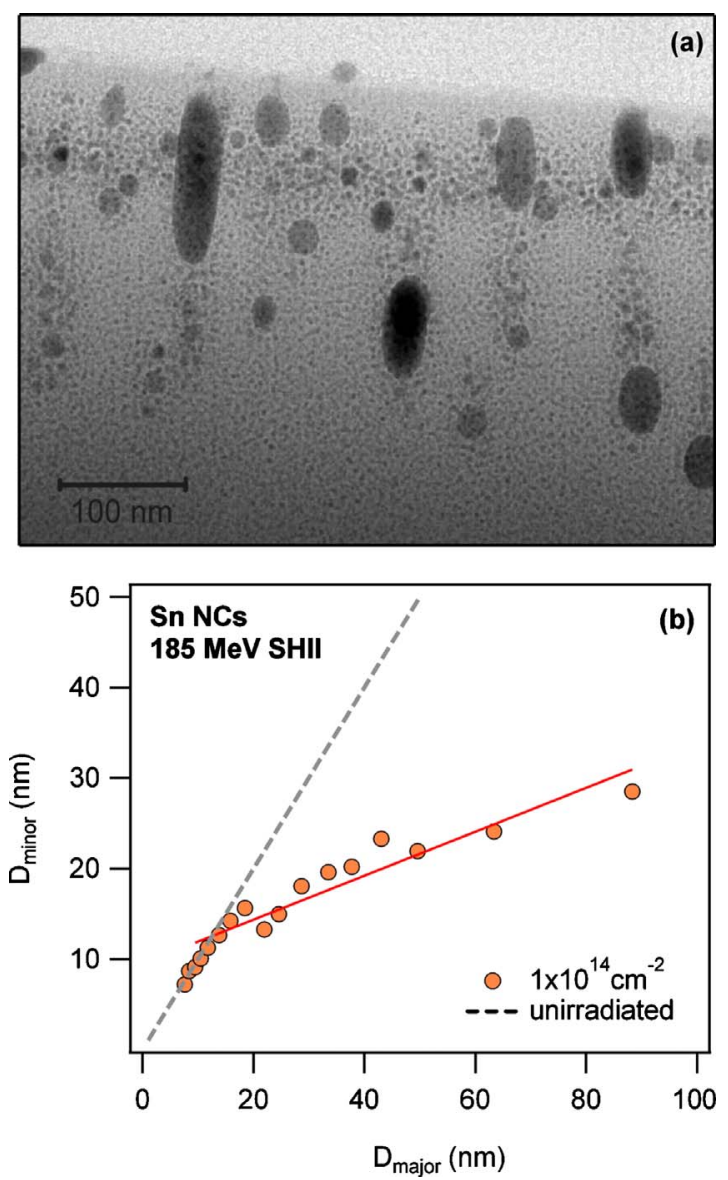

FIG. 1. (Color online) (a) TEM micrograph of Sn NCs embedded in $\mathrm{a}_{-} \mathrm{SiO}_{2}$ irradiated with $185 \mathrm{MeV} \mathrm{Au}$ ions to a fluence of $1 \times 10^{14} \mathrm{~cm}^{-2}$. (b) Minor $\left(D_{\text {minor }}\right)$ versus major $\left(D_{\text {major }}\right) \mathrm{NC}$ dimensions for the same irradiation parameters.

$1 \times 10^{14} \mathrm{~cm}^{-2}$. As previously demonstrated for $\mathrm{Pt}^{2,3} \mathrm{Au},{ }^{4}$ and $\mathrm{Co}$ (Ref. 11) NCs in a-SiO ${ }_{2}$, SHII also induces elongation of Sn NCs. Changes in NC shape are typically accompanied by NC dissolution, fragmentation, and coalescence, the extent of which depends on the ion fluence plus the NC composition and size.,17 As evident in Fig. 1(a), NC dissolution is very significant in the case of Sn where smaller spherical NCs have clearly replaced once-larger spherical NCs. Samples irradiated with twice the fluence $\left(2 \times 10^{14} \mathrm{~cm}^{-2}\right)$ exhibited almost complete NC dissolution (not shown). As above, dissolution is concomitant with elongation and the former impedes the direct observation of the saturation of $D_{\text {minor }}$ for Sn NCs. We are however able to estimate this value from results derived at lower fluence as explained below.

Figure 1(b) shows $D_{\text {minor }}$ as a function of $D_{\text {major }}$ for $\mathrm{Sn}$ NCs irradiated to a fluence of $1 \times 10^{14} \mathrm{~cm}^{-2}$. Individual values of $D_{\text {minor }}$ represent an average of $D_{\text {minor }}$ for all NCs of a given $D_{\text {major }}+/-1 \mathrm{~nm}$. NCs below a critical size remain spherical under irradiation while larger NCs elongate, as illustrated by the kink in the plotted data. The saturation of $D_{\text {minor }}$ would be manifested by a horizontal line post kink as previously observed for Pt NCs. ${ }^{2}$ The position of the kink at $D_{\text {minor }}=\sim 11 \mathrm{~nm}$ indicates this is the minimum particle size required for elongation and also serves as an estimate for the saturation value of $D_{\text {minor }}$. The correlation between $D_{\text {minor }}$ saturation and $D_{\text {track }}$ suggests that NC elongation is confined by the molten ion track in a-SiO ${ }_{2}$. NCs smaller than $D_{\text {track }}$ do not elongate or elongate at a significantly lesser rate given they are already effectively confined. Dissolution is promoted when the energy transferred from the incident ion to $\mathrm{NC}$ exceeds the cohesive energy of the metal atoms that comprise the NC. ${ }^{18}$ The formation of the smaller NCs subsequent to dissolution is then aided by the high mobility of $\mathrm{Sn}$ in a- $\mathrm{SiO}_{2}$, especially at elevated temperatures. ${ }^{15,19} \mathrm{We}$ suggest that the enhanced dissolution observed herein for $\mathrm{Sn}$ $\mathrm{NCs}$ is the result of the low cohesive energy (3.14 eV/atom) relative to the other metals we have studied including $\mathrm{Pt}$ (5.84 eV/atom), $\mathrm{Au}$ (3.81 eV/atom), and $\mathrm{Co}$ $(4.39 \mathrm{eV} / \mathrm{atom}){ }^{20}$ The metal solubility in both the solid and liquid phases of the matrix may also influence this result.

Figure 2 shows TEM micrographs of the second sample set with Sn NCs located at or in close proximity to the $\mathrm{a}-\mathrm{SiO}_{2} / \mathrm{c}-\mathrm{Si}$ interface, both before and after irradiation to a fluence of $1 \times 10^{14} \mathrm{~cm}^{-2}$. Prior to irradiation, the NCs are single crystalline with the metallic $\beta$-Sn structure. ${ }^{15}$ The majority of NCs exhibit a nearly spherical shape, particularly those completely surrounded by a- $\mathrm{SiO}_{2}$, with an average diameter of $\sim 12 \mathrm{~nm}$. Those NCs located at the interface have a lenticular shape with a fraction of their volume embedded in the c-Si substrate. After SHII, the NC shape transformation is readily apparent in Fig. 2(b). The NCs exhibit a prolate spheroid shape with the major dimension $\left(D_{\text {major }}\right)$ aligned with the direction of the incident ions. For the elongated NCs at the interface, traces of the original lenticular
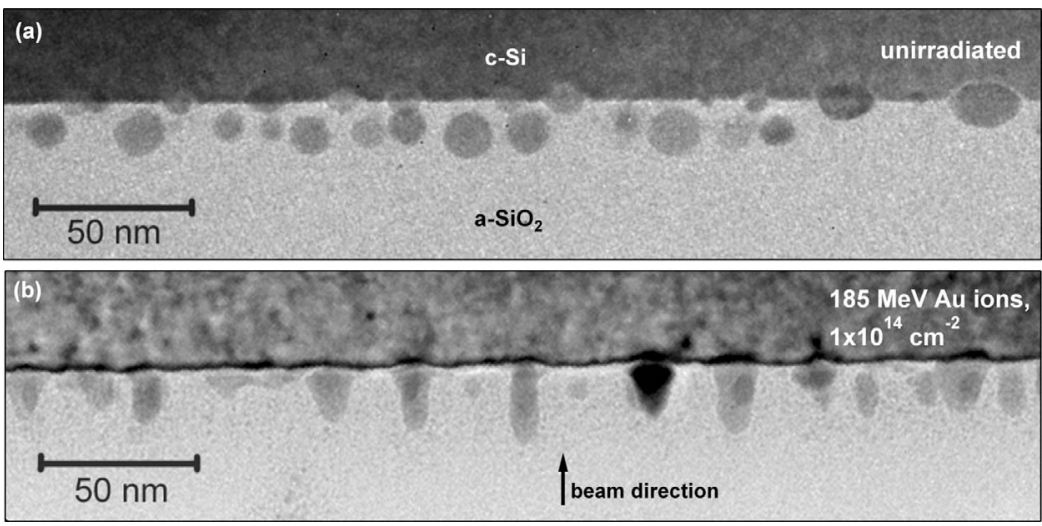

FIG. 2. TEM micrographs of Sn NCs at or in close proximity to the $\mathrm{SiO}_{2} / \mathrm{Si}$ interface, before and after irradiation to a fluence of $1 \times 10^{14} \mathrm{~cm}^{-2}$. 


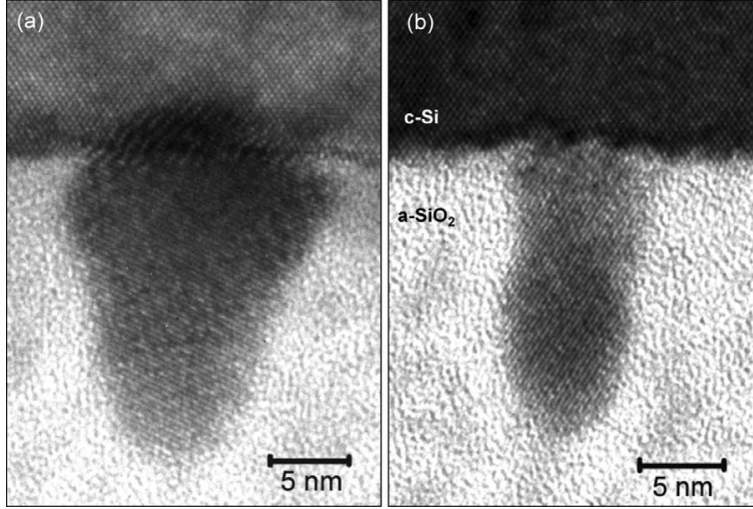

FIG. 3. High magnification TEM images of Sn NCs after SHII.

shape are retained and a fraction on their volume remains embedded in the c-Si substrate. There is no evidence of NC elongation within the c-Si substrate. Within the a-SiO${ }_{2}$, the average $D_{\text {minor }}$ of the elongated Sn NCs is $\sim 11 \mathrm{~nm}$, consistent with our estimate from the first sample set.

Figure 3 shows high-magnification images of two Sn NCs after irradiation. Both are single crystalline and of the same $\beta$-Sn phase as their unirradiated counterparts. That shown in Fig. 3(a) exhibits traces of the original lenticular shape, as above, and is elongated toward the sample surface (opposite to the incident ion direction). We suggest this $\mathrm{NC}$ was initially located at the $\mathrm{SiO}_{2} / \mathrm{Si}$ interface, partially embedded in both materials. The single crystallinity of the $\mathrm{NC}$ and the c-Si substrate facilitates the identification of the overlap between the two, as evidenced by the presence of Moiré fringes. Subsequent to SHII, a change in shape is readily apparent but only within the $\mathrm{a}-\mathrm{SiO}_{2}$ layer. Figure 3(b) shows a second Sn NC after SHII that we suggest was initially located within the $\mathrm{SiO}_{2}$ in close proximity to the a- $\mathrm{SiO}_{2} / \mathrm{c}-\mathrm{Si}$ interface. No overlap with the c-Si substrate is apparent. Again, a change in shape is readily apparent but the elongated $\mathrm{NC}$ does not extend within the c-Si and is confined to the a-SiO${ }_{2}$. SHII of such NCs clearly yields elongation in both directions and the NCs acquire the typical rodlike shape.

Our results support the hypothesis that the shape transformation of embedded metallic NCs by SHII is influenced by the properties of both the metal, as discussed above, and the surrounding matrix. ${ }^{2-4,10,21}$ As described below, we now suggest the irradiation of $\mathrm{Sn} \mathrm{NCs}$ located at the $\mathrm{a}-\mathrm{SiO}_{2} / \mathrm{c}-\mathrm{Si}$ interface demonstrates the necessity of a molten ion track in the elongation process. While $185 \mathrm{MeV} \mathrm{Au}$ ion irradiation readily yields a measurable ion track in $\mathrm{a}_{-} \mathrm{SiO}_{2},{ }^{14,22}$ such is not the case for $\mathrm{c}-\mathrm{Si}$. To form a molten ion track in a matrix, sufficient energy must be transferred between the electronic and lattice subsystems to induce melting in the latter. The efficiency with which this energy is transferred is quantified via the electron-phonon coupling constant $g$ which scales as $\left(1 / \lambda^{2}\right)$, where $\lambda$ is the electron-atom interaction mean-free path. ${ }^{23}$ Comparing amorphous and crystalline phases, the former is more sensitive to electronic excitation due to the reduced $\lambda$. In amorphous material, the transferred energy is thus more locally confined around the ion path and a greater lattice temperature is attained. A similar comparison of insulators and semiconductors demonstrates the former generally exhibits greater values of $g$ given $\lambda$ increases as the band gap decreases. ${ }^{23}$ As a consequence, the electron-phonon coupling constants of the amorphous insulator $\mathrm{SiO}_{2}$ $\left[1.25 \times 10^{13} \mathrm{~W} \mathrm{~cm}^{-3} \mathrm{~K}^{-1}\right.$ (Refs. 5 and 24)] and the crystalline semiconductor $\mathrm{Si}\left[1.8 \times 10^{12} \mathrm{~W} \mathrm{~cm}^{-3} \mathrm{~K}^{-1}\right.$ (Ref. 25)] differ considerably and, hence, ion track formation due to $185 \mathrm{MeV} \mathrm{Au}$ ion irradiation is only observed in a-SiO${ }_{2}$. SHII with single ions is thus an inefficient means of forming ion tracks in c-Si. ${ }^{26,27}$ In contrast, a much greater rate of electronic energy loss $(>25 \mathrm{keV} / \mathrm{nm})$ can be attained with $\mathrm{C}_{60}$ cluster ion irradiation ${ }^{25,28}$ which overcomes the weak electron-phonon coupling in c-Si and ion track formation can be achieved.

Our results also show that NCs can elongate in a direction opposite to that of the incident ion. Clearly the shape transformation is not a ballistic mechanism but instead is consistent with molten metal flow within the molten ion track formed in a-SiO ${ }_{2}$. Indeed, the thermal spike calculations of Awazu et al. ${ }^{5}$ for Au and D'Orleans et al. ${ }^{1}$ for Co demonstrate that metal $\mathrm{NCs}$ embedded in $\mathrm{a}-\mathrm{SiO}_{2}$ can indeed melt under SHII. We propose the shape transformation necessitates melting of both the metallic NC and insulating matrix followed by the flow of the former within the latter. The ensuing rapid quench of both the NC and matrix is such that the deformed NCs retain their elongated shape.

For our irradiation conditions, there is significant ion track overlap and elongation thus results from multiple ion-NC interactions. No evidence of an incubation fluence requirement has been observed. As previously demonstrated, NCs evolve in shape under SHII, gradually changing from spheres to prolate spheroids to rods. Our low irradiation flux $\left(\sim 5 \times 10^{10}\right.$ ions $\left./ \mathrm{cm}^{2} / \mathrm{s}\right)$ and the short-time frame for energy relaxation predicted by the thermal spike model ${ }^{5,23}$ is such that the energy deposited in each ion-NC interaction is dissipated before the next impact. The observed elongation is thus the sum of small incremental changes induced by individual ion-NC interactions.

\section{CONCLUSIONS}

In summary, we have investigated the effects of SHII on $\mathrm{Sn} \mathrm{NCs}$ embedded in $\mathrm{a}-\mathrm{SiO}_{2}$. The NCs changed shape after irradiation, becoming prolate spheroids or rods with their $D_{\text {major }}$ aligned in the direction of the incident ions. The dissolution of Sn NCs was more pronounced than that observed for other metals with higher melt temperatures and cohesive energies and hampered the saturation of $D_{\text {minor }}$. None the less, we estimated the $D_{\text {minor }}$ saturation and the threshold diameter for elongation of Sn NCs was $\sim 11 \mathrm{~nm}$, comparable to the diameter of the molten ion track in a- $-\mathrm{SiO}_{2}$. NCs located at or in close proximity to the $\mathrm{a}-\mathrm{SiO}_{2} / \mathrm{c}-\mathrm{Si}$ interface changed shape under irradiation but only within the $\mathrm{a}-\mathrm{SiO}_{2}$. We suggest the absence of an irradiation-induced molten ion track in $\mathrm{c}-\mathrm{Si}$ inhibited $\mathrm{NC}$ elongation within the substrate. 


\section{ACKNOWLEDGMENTS}

This work was financially supported by the Australian Research Council (ARC) and the Conselho Nacional de Desenvolvimento Científico e Tecnológico (CNPq). We thank the ANU Heavy Ion Accelerator Facility for their technical support and J. Fitzgerald and D. J. Llewellyn for assistance with the TEM measurements.
${ }^{1}$ C. D’Orléans, J. P. Stoquert, C. Estournes, C. Cerruti, J. J. Grob, J. L. Guille, F. Haas, D. Muller, and M. Richard-Plouet, Phys. Rev. B 67, 220101 (2003).

${ }^{2}$ R. Giulian, P. Kluth, L. L. Araujo, D. J. Sprouster, A. P. Byrne, D. J. Cookson, and M. C. Ridgway, Phys. Rev. B 78, 125413 (2008).

${ }^{3}$ R. Giulian, P. Kluth, D. J. Sprouster, L. L. Araujo, A. Byrne, and M. C. Ridgway, Nucl. Instrum. Methods Phys. Res. B 266, 3158 (2008).

${ }^{4}$ P. Kluth, R. Giulian, D. J. Sprouster, C. S. Schnohr, A. P. Byrne, D. J. Cookson, and M. C. Ridgway, Appl. Phys. Lett. 94, 113107 (2009).

${ }^{5}$ K. Awazu, X. M. Wang, M. Fujimaki, J. Tominaga, H. Aiba, Y. Ohki, and T. Komatsubara, Phys. Rev. B 78, 054102 (2008).

${ }^{6}$ J. J. Penninkhof, T. van Dillen, S. Roorda, C. Graf, A. van Blaaderen, A. M. Vredenberg, and A. Polman, Nucl. Instrum. Methods Phys. Res. B 242, 523 (2006).

${ }^{7}$ Y. K. Mishra, F. Singh, D. K. Avasthi, J. C. Pivin, D. Malinovska, and E. Pippel, Appl. Phys. Lett. 91, 063103 (2007).

${ }^{8}$ E. A. Dawi, G. Rizza, M. P. Mink, A. M. Vredenberg, and F. Habraken, J. Appl. Phys. 105, 074305 (2009).

${ }^{9}$ A. Oliver, J. A. Reyes-Esqueda, J. C. Cheang-Wong, C. E. Roman-Velazquez, A. Crespo-Sosa, L. Rodriguez-Fernandez, J. A. Seman, and C. Noguez, Phys. Rev. B 74, 245425 (2006).

${ }^{10}$ M. C. Ridgway, P. Kluth, R. Giulian, D. J. Sprouster, L. L. Araujo, C. S. Schnohr, D. J. Llewellyn, A. P. Byrne, G. J. Foran, and D. J. Cookson, Nucl. Instrum. Methods Phys. Res. B 267, 931 (2009).

${ }^{11}$ D. J. Sprouster, R. Giulian, C. S. Schnohr, L. L. Araujo, P. Kluth, A. P. Byrne, G. J. Foran, B. Johannessen, and M. C. Ridgway, Phys. Rev. B 80, 115438 (2009).

${ }^{12}$ D. Katz, T. Wizansky, O. Millo, E. Rothenberg, T. Mokari, and U. Banin, Phys. Rev. Lett. 89, 086801 (2002).

${ }^{13}$ H. Htoon, J. A. Hollingworth, A. V. Malko, R. Dickerson, and V. I. Klimov, Appl. Phys. Lett. 82, 4776 (2003)

${ }^{14}$ P. Kluth, C. S. Schnohr, O. H. Pakarinen, F. Djurabekova, D. J.
Sprouster, R. Giulian, M. C. Ridgway, A. P. Byrne, C. Trautmann, D. J. Cookson, K. Nordlund, and M. Toulemonde, Phys. Rev. Lett. 101, 175503 (2008).

${ }^{15}$ F. Kremer, J. M. J. Lopes, F. C. Zawislak, and P. F. P. Fichtner, Appl. Phys. Lett. 91, 083102 (2007).

${ }^{16}$ J. F. Ziegler, J. P. Biersack, and U. Littmark, The Stopping and Range of Ions in Solids (Pergamon Press, New York, 1985).

${ }^{17}$ D. J. Sprouster, R. Giulian, L. L. Araujo, P. Kluth, B. Johannessen, N. Kirby, K. Nordlund, and M. C. Ridgway, Phys. Rev. B 81, 155414 (2010).

${ }^{18}$ S. Bayan and D. Mohanta, J. Mater. Res. 25, 814 (2010).

${ }^{19}$ J. M. J. Lopes, F. C. Zawislak, P. F. P. Fichtner, F. C. Lovey, and A. M. Condo, Appl. Phys. Lett. 86, 023101 (2005).

${ }^{20}$ C. Kittel, Introduction to Solid State Physics (Wiley, Hoboken, 2005).

${ }^{21}$ P. Kluth, B. Johannessen, R. Giulian, C. S. Schnohr, G. J. Foran, D. J. Cookson, A. P. Byrne, and M. C. Ridgway, Radiat. Eff. Defects Solids 162, 501 (2007).

${ }^{22}$ S. Klaumunzer, Nucl. Instrum. Methods Phys. Res. B 225, 136 (2004).

${ }^{23}$ M. Toulemonde, C. Dufour, and E. Paumier, Acta Phys. Pol. A 109, 311 (2006).

${ }^{24}$ M. Toulemonde, J. M. Costantini, C. Dufour, A. Meftah, E. Paumier, and F. Studer, Nucl. Instrum. Methods Phys. Res. B 116, 37 (1996).

${ }^{25}$ A. Chettah, H. Kucal, Z. G. Wang, M. Kac, A. Meftah, and M. Toulemonde, Nucl. Instrum. Methods Phys. Res. B 267, 2719 (2009).

${ }^{26}$ M. Toulemonde, J. Dural, G. Nouet, P. Mary, J. F. Hamet, M. F. Beaufort, J. C. Desoyer, C. Blanchard, and J. Auleytner, Phys. Status Solidi A 114, 467 (1989).

${ }^{27}$ M. Levalois, P. Bogdanski, and M. Toulemonde, Nucl. Instrum. Methods Phys. Res. B 63, 14 (1992).

${ }^{28}$ A. Dunlop, G. Jaskierowicz, and S. Della-Negra, Nucl. Instrum. Methods Phys. Res. B 146, 302 (1998). 